\title{
Discurso e imagem:
} possibilidades metodológicas para uma análise discursiva do fotojornalismo contemporâneo

\author{
Nelson Soares \\ Doutor; Universidade Federal do Oeste da Bahia, Santa Maria da Vitória, BA, Brasil \\ nsoares@outlook.com
}

\section{Giovandro Marcus Ferreira}

Doutor; Universidade Federal da Bahia, Salvador, BA, Brasil

giovandro.ferreira@gmail.com

\section{Resumo}

Sabe-se que as diferentes abordagens desenvolvidas no interior da Análise de Discurso se ocuparam principalmente com práticas discursivas elaboradas a partir de materiais linguísticos, - que tornam bastante consistentes as possibilidades metodológicas voltadas para o estudo de textos verbais, como ocorre com a literatura, o jornalismo impresso ou publicidade, por exemplo. A partir desse cenário, apresentamos os limites e as possibilidades de uma metodologia de análise da imagem fotojornalística, fundamentada em uma visão discursiva da linguagem. Para tanto, o estudo propõe uma metodologia que considera os pressupostos teóricos da Análise de Discurso e as possíveis contribuições da psicologia da percepção, desenvolvidas por Ernst Gombrich para o estudo do fotojornalismo. Tem-se, então, como resultado, um conjunto formado por três categorias de análise do fotojornalismo, que considera as implicações históricas e ideológicas e suas relações com a matéria não verbal na constituição da semiose do jornalismo impresso.

\section{Palavras-chave}

Fotojornalismo. Análise de discurso. Enunciação. Posicionamento discursivo. Psicologia da percepção. 


\section{Introdução}

Mesmo considerando a forte influência da Linguística na configuração da Análise de Discurso (ORLANDI, 1999), sabe-se que a noção de discurso não tem sua aplicação restrita a textos verbais, escritos ou falados, mas antes evidencia a postura assumida pelo analista diante do exercício da linguagem, como bem assinala Maingueneau (1998, p. 43): “[...] esse termo [discurso] designa menos um campo de investigação delimitado do que um certo modo de apreensão da linguagem [...]".

Ainda que o conceito de discurso e seus pressupostos teóricos tenham aplicabilidade em materiais significantes de diversas naturezas, percebe-se a necessidade (e a dificuldade) de estabelecer mecanismos metodológicos que permitam o estudo da imagem a partir de uma perspectiva discursiva. Se considerarmos ainda o estudo dos discursos engendrados pelos meios de comunicação de massa, tal necessidade metodológica ganha maior importância, pois a diversidade de materiais significantes aí existentes dá origem a discursos heterogêneos, nos quais encontramos diversos tipos de imagens, fixas ou em movimento.

Dessa forma, constata-se que o uso da imagem em discursos sociais ${ }^{1}$ dificilmente acontece de maneira isolada, sem relação direta com o texto verbal. Consequentemente, o desenvolvimento de uma metodologia de análise da imagem nos meios de comunicação demanda a consideração de sua estreita interação com o linguístico e o cuidado com esse aspecto deve estar presente na postura do analista ao estudar o fotojornalismo.

\section{Discurso e imagem}

Além da necessária relação entre fotografia de imprensa e texto verbal, preocupanos o estabelecimento de uma metodologia que busque na imagem fotográfica sua potencialidade discursiva e enunciativa. Não nos interessa, então, uma abordagem que ponha a perder as especificidades da imagem - seus elementos próprios, tais como cor, perspectiva, composição e enquadramento, luz, textura, pose entre outros -, ou um modo de compreensão de seu funcionamento que imponha um regime estritamente submetido à lógica da significação linguística.

\footnotetext{
${ }^{1}$ Discursos mistos, de natureza heterogênea, produzidos e circulantes no conjunto social (PINTO, 1995).
} 
Interessa-nos, assim, estabelecer uma metodologia que avance na explicação dos mecanismos de funcionamento da imagem fotográfica, sem opor sistematicamente o verbal à imagem, mas também considerando o que há em comum em seus processos de significação, como nos explica Christian Metz:

As 'linguagens' visuais mantêm com as outras laços sistemáticos que são múltiplos e complexos, e nada se ganha em opor o 'verbal' e o 'visual' como dois grandes blocos, cada qual homogêneo, maciço, e desprovido de ponto de contato com o outro. (METZ, 1973, p. 12).

Nessa busca por "estruturas linguísticas que estão subterrâneas à obra, na própria imagem", como sugere Metz (1973, p. 9), propomos buscar no fotojornalismo, da mesma forma que na língua, traços que nos permitam recompor o momento do engendramento do discurso - ou seja, o estudo da enunciação fotojornalística. A indicação desses mecanismos, a partir da própria imagem fotográfica e/ou de sua relação com elementos verbais, permitenos pôr em evidência os recursos acionados na produção de sentido das fotografias de imprensa.

A esse respeito, sabe-se que os elementos constituintes da enunciação não são exclusivos das línguas, mas estão presentes em todas as linguagens, variando os mecanismos utilizados para sua expressão, conforme explica José Luiz Fiorin (1999). Trazendo essa problemática para o estudo da imagem fotográfica, vê-se a necessidade de insistirmos na apreciação de seu funcionamento discursivo enquanto matéria significante visual, destacando sua relação com o texto, mas também tendo em conta uma relativa autonomia da imagem.

Trabalhando nesta perspectiva - e considerado um marco no estudo da significação em fotografia -, é possível destacar as pesquisas de Roland Barthes. Com estudos fortemente marcados por uma visão estruturalista do signo, de filiação saussureana, Barthes nos oferece, entre outros textos, dois importantes artigos acerca da significação em fotografia de imprensa e de publicidade, a saber: A Mensagem Fotográfica, originalmente publicado em 1961, e A Retórica da Imagem, de 19642.

Nesses dois trabalhos, Barthes (1990a, 1990b) desenvolve uma metodologia para o estudo da fotografia circulante nos meios de comunicação de massa, na qual elementos importantes são contemplados: a interação entre texto verbal e fotografia - acerca deste aspecto o autor propõe dois tipos de relação: fixação e relais - e a compreensão da fotografia

${ }^{2}$ Artigos originalmente publicados na revista Communications. 
em três dimensões de significação - (1) as mensagens verbal, (2) denotativa e (3) conotativa.

Em (1) temos os elementos linguísticos, que podem ser de dois tipos: internos à imagem (uma faixa trazendo palavras de ordem em uma fotografia de manifestantes grevista ou o nome da marca de um produto em uma fotografia publicitária, por exemplo) ou externos à fotografia (legenda, manchete ou o próprio artigo, no caso de fotojornalismo; título, corpo de texto ou slogan, no caso da publicidade). Em (2), a mensagem denotativa, encontramos a dimensão analógica da imagem fotográfica - "o seu analogon perfeito" (BARTHES, 1990a, p. 12), que, para o senso comum, caracteriza de modo singular a fotografia.

A dimensão denotativa da fotografia está relacionada ao plano descritivo da imagem e responde a pergunta "O que a imagem nos monstra?". Ligada à percepção e ao reconhecimento, a denotação fotográfica é a mensagem primeira, responsável pela identificação dos elementos representados (LIMA, 1988; JOLY, 1996), que se estende por todo o contínuo da imagem e é desprovida de código (BARTHES, 1990a).

Indo além do nível denotativo, há (3), uma mensagem segunda - a mensagem conotada -, construída sobre a dimensão denotativa da imagem. Historicamente desenvolvida, codificada e descontínua, a conotação fotográfica se constitui a partir da cultura partilhada entre produtores e leitores - localizando-se, dessa forma, no espaço e no tempo. É na mensagem conotada, situada para além da analogia, que se podem agregar à fotografia outros sentidos, tanto no processo de produção da imagem quanto em sua edição (BARTHES, 1990b).

No entanto, sua abordagem estruturalista do objeto - que até os dias de hoje é influência marcante nos estudos do fotográfico - impõe uma excessiva segmentação da imagem, pondo em risco suas especificidades. É bem verdade que o autor declara que tal divisão proposta em seu método é apenas operatória, na qual a distinção entre as duas mensagens, denotativa e conotativa, é simplesmente um recurso do analista, mas esta concepção de Barthes acaba por enfatizar uma subdivisão da imagem. Por isso mesmo, essas duas dimensões da significação fotográfica - denotação e conotação - não devem ser compreendidas como categorias estanques, sem conexão, mas antes devem ser tomadas como instâncias integradas e responsáveis pela produção de um sentido global e interdependente - o que deve ser considerado no momento da análise. 
Além dessas pesquisas desenvolvidas no período de consolidação da semiologia, Barthes nos oferece outro trabalho de grande importância nesse campo e que, até os dias atuais, é fundamental nos estudos da imagem fotográfica. Trata-se de $A$ câmara clara - nota sobre a fotografia, seu último livro, publicado pouco depois de sua morte, em 1980, a pedido dos Cahier du Cinéma.

Nesta obra de Barthes (1984), o leitor não irá encontrar um trabalho nos moldes estritamente acadêmicos. Nela, o autor nem mesmo propõe um objeto específico, um corpus de análise devidamente delimitado, mas opta por tomar como fonte de discussão algumas fotografias escolhidas dentro de critérios bastante pessoais; ele inclui imagens de fotógrafos consagrados - como, por exemplo, Alfred Stieglitz, Richard Avedon, Félix Nadar, Robert Mapplethorpe, André Kertész, dentre outros - e também fotografias particulares, como aquelas de sua mãe. Em A câmera clara - texto que o semiólogo escreve sempre em primeira pessoa, com um estilo solto, à maneira de um ensaio - Barthes se preocupa fundamentalmente em aprofundar uma ontologia da imagem fotográfica: "[...] eu queria saber a qualquer preço o que ela [a fotografia] era 'em si', por que traço essencial ela se distinguia da comunidade das imagens." (BARTHES, 1984, p. 12).

E, nesta perspectiva, Barthes abre o livro com uma discussão que nos dá uma dimensão de suas indagações acerca do fotográfico: “Um dia, há muito tempo, dei com uma fotografia do último irmão de Napoleão, Jerônimo. Eu me disse então, com um espanto que jamais pude reduzir: 'Vejo os olhos que viram o imperador."' (BARTHES, 1984, p. 11). Assim, deparamo-nos com uma observação feita na década de 1960, ainda em A retórica da imagem, que diz respeito à aproximação extrema que há entre a fotografia e seu referente, de tal forma que, ao olharmos para a imagem fotográfica, não vemos a fotografia, mas o objeto mesmo. Dentro de suas conclusões, o autor concebe a fotografia como a marca daquilo que já foi, do fato ou coisa que "esteve lá" e que, graças à mágica do dispositivo fotográfico, é congelado e lançado ao infinito. Ou seja, a fotografia é a denúncia do tempo passado, da morte, de tudo que já foi; nas palavras de Barthes: “[...] o Particular absoluto, a Contingência soberana."(BARTHES, 1984, p. 13).

Como defende Barthes (1984, p. 129), "Toda fotografia é um certificado de presença.". Assim, a qualidade particular da fotografia não é indicar "aquilo que não é mais", mas sim "aquilo que foi", aquilo que de algum modo necessariamente existiu ou aconteceu. Em outras palavras, a fotografia conjuga duas propriedades: convoca o passado e atesta uma realidade (BARTHES, 1984, p. 115). 
A fim de apresentar seu pensamento, Barthes distingue três possibilidades de abordagem da fotografia: fazer, suportar e olhar. A primeira abordagem, o fazer, refere-se à prática do fotógrafo (que o autor chama de Operator); a segunda, o suportar (que o autor chama de Spectrum), refere-se ao ato de nos colocarmos diante da câmera, de nos fazermos imagem; a terceira, o olhar (que o autor chama de Spectator), refere-se à nossa prática de ver e consumir imagens fotográficas em livros, jornais, revistas e cartazes, por exemplo. Isto posto, Barthes se abstém de discutir sob o ponto de vista do Operator, uma vez que não era fotógrafo, nem mesmo amador. Sua abordagem, então, tem início a partir dos outros dois referenciais: o sujeito olhado e o sujeito que olha (BARTHES, 1984).

Por mais que A Câmara Clara seja uma obra de caráter pessoal, na qual Barthes parte de observações de sua vida particular, várias são suas contribuições no sentido mesmo de uma fenomenologia da fotografia. É bem verdade que as questões da significação da fotografia no contexto dos meios de comunicação de massa não são tratadas de forma direta, mas esse último livro traz muitos avanços, sobretudo no que se refere à temporalidade como elemento central da significação fotográfica. Em certos aspectos, podemos dizer que Barthes antecipa questões relevantes na distinção que se pode fazer entre a fotografia e as outras formas de imagens, como é o caso desta passagem: “[...] um retrato pintado, por mais semelhante que seja, não é uma fotografia." (BARTHES, 1984, p. 25). Aqui, Barthes sinaliza para uma definição da fotografia ancorada não mais no seu poder extremo de semelhança - na sua iconicidade -, mas antes, na relação de implicação causal que a fotografia estabelece com seu referente - na sua indicialidade; definição esta que será muito bem explorada por Philippe Dubois, em seu livro de 1994, $O$ ato fotográfico.

Nesta obra fundamental aos estudos em fotografia - vista pelo próprio autor como pós estruturalista e claramente fundamentada na noção peirceana de índice -, Dubois (1994) traz algumas contribuições ao entendimento da imagem fotográfica em seu aspecto ontológico e na sua relação com a história da arte (principalmente com a arte contemporânea). Dentre elas podemos destacar a evolução do pensamento sobre o dispositivo fotográfico e a sua concepção da fotografia enquanto ato (de produção e recepção), com base na lógica que a faz ser, que a distingue das outras imagens.

Com relação à evolução dos discursos sobre o dispositivo e seu valor dentro da cultura, Dubois (1994) distingue três momentos (ou três pensamentos): o discurso da mimese, o discurso da transformação do real e, por último, o discurso da fotografia como traço do real. No discurso da mimese - que marca o século XIX - à fotografia é dado o lugar 
máximo da imitação, da reprodução fiel e objetiva do real. Nessa época a concepção da fotografia era baseada fundamentalmente no seu valor de ícone, na sua semelhança. Esse foi o momento que assistiu o rápido crescimento e popularização da fotografia, de tal forma que, em algumas práticas sociais - principalmente o retrato -, ela chega praticamente a substituir a pintura (FREUND, 1989). Acontece, assim, a proliferação dos estúdios de fotografia em Paris e a compulsão da pequena burguesia em adquirir retratos fotográficos, dado que estes possuíam preços bem mais acessíveis. Nesse contexto - no qual se viu com relativa rapidez os pintores substituírem a palheta de cores pela parafernália do aparelho fotográfico - os discursos, muitas vezes inflamados, opunham arte e fotografia. A arte, ao contrário da fotografia, era marcada pela criação, pela força do imaginário, baseada no trabalho manual e artesanal, enquanto a fotografia era caracterizada pela objetividade, sendo vista como uma simples cópia do real, em que o trabalho do gênio humano era substituído pela ação fria da máquina.

Entretanto, com o passar do tempo, Dubois (1994) destaca a prevalência de outra ordem de discursos acerca da fotografia. Assim, dominando uma parte do séc. XX, temos o discurso da transformação do real. Neste momento, a percepção da fotografia como essencialmente marcada pela semelhança dá lugar a um pensamento diametralmente oposto, no qual a imagem fotográfica é vista como modificação e, algumas vezes, como deturpação do real. Podemos, então, destacar entre as diversas manifestações deste momento aqueles discursos baseados nas teorias da percepção e os claramente marcados pelo traço ideológico. Rudolf Arnheim (19573 apud DUBOIS, 1994, p. 38) elenca diversos elementos que fazem da fotografia não uma reprodução exata, mas uma modificação na aparência do real. Entre os pontos destacados por Arnheim, temos o enquadramento como elemento selecionador do que será representado, a mudança do tridimensional (o objeto) para a superfície bidimensional da fotografia, a redução cromática do real à escala tonal de cinzas que compõem a imagem fotográfica em preto e branco e a exclusão dos demais sentidos, permanecendo apenas a experiência visual ou visual-sonora (no caso do cinema).

Ou seja, esta linha de pensamento descaracteriza a ideia de reprodução direta do real, na direção de uma percepção parcial do real, tendo, assim, uma certa modificação. No segundo caso, nas argumentações marcadas pela questão da ideologia, Dubois nos traz, entre outros, Bourdieu. De acordo com Dubois (1994), o sociólogo propõe os argumentos trabalhados por Arnheim - que reforçam uma redução em termos de cor e profundidade - e

${ }^{3}$ ARNHEIM, Rudolf. Film and reality. In: ARNHEIM, Rudolf. Film as art. Los Angeles: California Press, 1957. 
também destaca a determinação imposta pelo enquadramento, uma vez que este indica os aspectos do real e o momento exato que leitor da imagem terá acesso à cena. Além disso, Bourdieu (apud DUBOIS, 1994) sustenta que a fotografia só é vista como o real objetivo por que foi determinado a ela esta função dentro da sociedade: servir de imitação objetiva do mundo.

Contudo, o autor de $O$ ato fotográfico, ainda destaca um terceiro discurso, o da fotografia como traço do real. Enquanto o primeiro momento - o discurso da mimese caracterizou-se pela ancoragem da fotografia na sua semelhança com o referente (uma relação fundamentalmente icônica) e o segundo momento - o discurso da transformação do real - foi marcado pela sua modificação do objeto, em que a semelhança é apreendida na cultura, como uma convenção ou acordo geral da sociedade (uma relação fundamentalmente simbólica), o terceiro momento traz um novo fator: a definição da fotografia não está mais centrada na sua semelhança, seja ela natural e imediata (icônica) ou convencional e arbitrária (simbólica), mas na sua gênese, no processo que a faz ser. Assim, o discurso sobre o caráter da fotografia toma outro rumo, baseando-se na sua singularidade frente a outras imagens, a saber, a relação de contiguidade física entre o objeto-referente e a fotografia. Trata-se, então, de uma relação indicial que se constrói na sua lógica físico química, em que o objeto necessariamente precisa ter estado diante da máquina fotográfica para refletir luz em direção à superfície fotossensível e, com isso, produzir a imagem. (DUBOIS, 1994).

Assim, caracterizando o processo fotográfico de uma forma mais precisa, Dubois sustenta que esta última definição da fotografia - de uma conexão física com o real (relação de índice) - é, de fato, o que garante sua distinção entre as demais imagens e nos dá a impressão de vermos o objeto. Além disso, esta concepção da fotografia com base no seu processo de conexão física lhe garante um status de imagem-ato, no qual sua compreensão e recepção são preenchidas por este sentido de singularidade (atestação) e de imagem em processo. E é importe ainda frisar que a imagem fotográfica é necessariamente pensada enquanto conjunto, não cabendo uma divisão entre o processo e produto. $\mathrm{Ou}$ seja, a fotografia abre espaço a uma nova forma de pensar a imagem - "o fotográfico", nas palavras do autor; uma forma de pensar que envolve, indissociavelmente, relações sígnicas, temporais e espaciais, em que estão implicados o sujeito, o ser e o fazer (DUBOIS, 1994, p. $60)$. 
Ainda que as pesquisas de Barthes (1984, 1990a, 1990b) e Dubois (1994) nos ajudem a compreender a significação da imagem fotográfica, a problemática dos efeitos de sentido da fotografia nos meios de comunicação de massa, com destaque para o fotojornalismo, não fica resolvida se considerarmos a perspectiva discursiva, já que as propostas de origem estruturalista ainda são demasiadamente imanentistas. Propomos, assim, aliar os estudos desenvolvidos por Barthes e Dubois, juntamente com o arcabouço teórico da Análise do Discurso, aos estudos da psicologia da percepção, como será exposto a seguir.

\section{A produção de sentido no fotojornalismo}

A fim de resguardar as propriedades específicas da fotografia e prover a abordagem discursiva de conceitos e noções adequados à significação da imagem, propomos considerar alguns princípios desenvolvidos por Ernst Gombrich, a partir da psicologia da percepção.

Dedicando seus estudos a questões sobre representação visual, psicologia da percepção e interpretação das imagens, o vienense E. Gombrich é considerado, no campo das teorias da arte, um dos maiores pesquisadores do século $\mathrm{XX}$, tendo publicado, entre outros estudos, Arte e Ilusão, de 1995, e Meditações sobre um Cavalinho de Pau, de 1999.

Embora seus estudos não estejam relacionados com a Análise de Discurso ou com as imagens presentes nos meios de comunicação, é possível perceber que há em Arte e Ilusão questões vinculadas ao problema da semelhança nas imagens fixas, à interpretação de imagens e à relação destas com o espectador. E mesmo trazendo exemplos próprios do campo das artes, tais estudos se mostram importantes para a compreensão do fotojornalismo, pois um de seus objetivos é explicar quais mecanismos são acionados pelo espectador quando da leitura de imagens fixas.

Apesar de termos aqui - nessa aproximação entre as pesquisas de Gombrich (1995, 1999) e a abordagem discursiva dos fenômenos da comunicação nos mídias - origens diversas e dois campos de conhecimento distintos, é importante observar que esse autor considera pontos importantes aos estudos da Análise de Discurso, tais como: a influência da cultura e do contexto na interpretação da imagem, a participação ativa do leitor na produção de sentido, a influência do texto verbal para o processo de leitura da imagem e a interdependência entre produtores e leitores na produção de sentido. Dessa forma, esse artigo propõe possíveis aproximações e aplicações de alguns conceitos - estereótipo adaptado, princípio do etc. e padrão de correção, por exemplo - desenvolvidos por 
Gombrich em Arte e ilusão. Tais noções referem-se ao processo de produção ou leitura de imagens, como podemos perceber a partir da ideia de estereótipo adaptado.

Explicando os processos que envolvem a produção de imagens, a noção de estereótipo adaptado nos mostra a estreita relação entre fórmulas verbais e representações visuais. Segundo o autor, ao classificarmos uma determinada imagem em uma categoria já existente, torna-se mais fácil a sua reprodução. Em outras palavras, durante o processo de produção de imagens, tende-se a buscar um vínculo com um padrão - um estereótipo existente - estabilizado na cultura, requerendo, tão somente, o trabalho de adaptá-lo às necessidades do momento. A título de exemplo, Gombrich nos aponta um jornal alemão publicado no século XVI, no qual encontramos a informação de uma inundação em Roma. Acompanhando a notícia, há uma ilustração (xilogravura) do castelo Sant'Angelo, quase sendo atingido pelas águas do rio Tibre. Tal representação, claramente influenciada pelos estereótipos conhecidos por seu produtor, traz elementos próprios dos burgos alemães. E, a partir daí, pode-se compreender que o autor da referida ilustração tomou como base, em seu repertório de modelos mentais, aquele que melhor poderia se adaptar à ideia do castelo. (GOMBRICH, 1995).

Certamente, no caso da fotografia de imprensa - e mesmo da fotografia de uma maneira geral -, o produtor da imagem não desempenha seu papel da mesma forma que Gombrich (1995) nos fala a respeito do gravador alemão do século XVI. Entretanto, o processo de significação (e produção) da imagem fotográfica, dentro dos dispositivos da comunicação de massa (jornalismo e publicidade, por exemplo), segue padrões mentais e estereótipos que se referem a particularidades da técnica fotográfica e de seus usos historicamente constituídos no interior do discurso dos meios de comunicação de massa.

Os estereótipos que orientam o trabalho do repórter fotográfico estão relacionados principalmente a dois fatores: primeiramente, aos padrões formais herdados das técnicas de representação pictóricas, como é o caso da pintura (FREUND, 1989) - aqui, referimo-nos a princípios de composição, iluminação e enquadramento, entre outros; em segundo lugar, temos a orientação editorial implementada pelo periódico, que já aponta para procedimentos de construção de imagens desenvolvidos ao longo do tempo, na relação que se estabelece entre o suporte jornalístico e seus leitores - tais orientações editoriais remetem tanto para o aspecto formal das fotografias como para as relações entre imagem, texto e diagramação, por exemplo (VERÓN, 1983). 
Conforme evidencia Gombrich (1995), o autor da imagem dá início ao seu trabalho com um conceito - o estereótipo daquilo que será fotografado - já estabelecido. Em seguida, agrega os traços distintivos e as adaptações necessárias àquilo que está sendo retratado. Ou seja, o fotógrafo já tem um conceito previamente estabelecido de imagem para o discurso político, para o suspeito de homicídio, para a manifestação grevista e para a partida de futebol - tanto em relação a seus aspectos plásticos, quanto em relação às interações entre texto e fotografia, também responsáveis pelo efeito de sentido.

Dependendo, então, da situação, o repórter fotográfico faz a devida adaptação do seu modelo mental, tendo em conta fatores como: a função da imagem (qual editoria e que relação ela deve ter com o fato representado), a linha editorial desenvolvida pelo suporte jornalístico, as especificidades da própria cena, que impõem limites físicos e técnicos ao trabalho do fotógrafo (o equipamento disponível, acesso ao local do acontecimento, luminosidade e tempo, entre outros). Dessa maneira, o autor trabalha como quem preenche os "espaços vazios de um formulário" (GOMBRICH, 1995, p. 77).

Se a noção de estereótipo adaptado explica como certos sentidos se tornam mais ou menos ajustáveis - o que permite a utilização de modelos modificáveis para situações específicas -, outra noção, esta mais própria do referencial teórico da Análise do Discurso, pode também ser aplicada a este caso: trata-se da noção de interdiscurso ${ }^{4}$. Contudo, entendemos que a noção desenvolvida por Gombrich (1995) evidencia mais claramente o processo de produção e leitura da imagem, além de permitir uma abordagem mais sistemática, uma vez que identificar os discursos outros que são resgatados em um dado engendramento discursivo é tarefa que muitas vezes carece de precisão.

Enquanto a noção de estereótipo adaptado nos aponta para uma melhor compreensão do processo de produção de imagens, a ideia de princípio do etc., também desenvolvida por Gombrich (1995), orienta-nos a respeito da relação entre o leitor e o discurso visual - o que, em última instância, influencia o trabalho de fotógrafos e editores.

De acordo com o princípio do etc., para a produção de sentido através de uma imagem não é necessário que esta seja exaustivamente detalhada, pois, em seu processo de interpretação, o leitor não precisa analisar toda a extensão da imagem para lhe atribuir sentido. Isso ocorre porque tendemos a pensar que "ver alguns elementos de uma série é vêlos todos". (GOMBRICH, 1995, p. 230).

\footnotetext{
4 Considerando-se um determinado discurso, podemos dizer que interdiscurso é o conjunto de unidades discursivas, deslocadas no tempo e no espaço, aos quais ele faz referência (MAINGUENEAU, 1998).
} 
Com isso, entendemos que o leitor de um jornal impresso não lê detalhadamente as imagens publicadas, da mesma forma como não lê todas as páginas do periódico. Como evidencia Lorenzo Vilches (1987), se o regime de leitura da televisão, por exemplo, está preso à sequência de programas e a continuidade temporal, no caso do jornal impresso, é possível o leitor "pular" uma página ou matéria, seguir para sua editoria preferida, traçando, assim, seu percurso particular de leitura. Ainda nessa perspectiva, em uma mesma página é possível encontrar diversos percursos de leitura: ver uma fotografia, ir ao título da matéria e seguir adiante; ler apenas o título da matéria e a legenda que acompanha a fotografia; ler apenas a legenda e analisar a fotografia, por exemplo. (VILCHES, 1987, p. 54-55). Percebe-se, então, que uma leitura exaustiva do jornal impresso dificilmente ocorre e, consequentemente, a leitura de uma imagem fotográfica é, da mesma maneira, rápida e superficial. Assim, alguns pormenores figurativos não são vistos, mas inferidos em relação a outros elementos presentes na mesma imagem fotográfica.

Nesta perspectiva das relações entre leitor e imagem, Gombrich propõe entendermos a interpretação como um exercício de projeção, no qual é necessário que o leitor lance uma hipótese inicial a respeito do efeito de sentido da imagem. Logo em seguida, esta hipótese inicial passa por uma verificação mais cuidadosa - etapa que o autor chama de teste de consistência -, que implica na classificação da imagem em alguma categoria da experiência humana (GOMBRICH, 1995). Este trabalho de verificação do sentido proposto para a imagem é feito por etapas, que dependem da capacidade do olho humano em assimilar a informação visual. Desta maneira, o leitor segue através da imagem compondo um conjunto de elementos significantes, muitos deles isolados, que, ao final, poderão ou não confirmar sua ideia inicial acerca do sentido da imagem (GOMBRICH, 1999).

Exemplificando a noção de teste de consistência, o autor apresenta-nos a imagem a seguir (Figura 1), na qual encontramos uma mesma linha horizontal que adquire significados variados, de acordo a situação em que se encontra. Em um primeiro momento, esta linha funciona como o percurso do trem, depois como a borda de uma mesa e, por fim, aparece como ângulo reto de uma parede. Na verdade, o que temos neste desenho é uma brincadeira baseada em nossa capacidade de atribuir sentido de acordo com o contexto e os elementos internos de uma imagem. 
Figura 1 - Desenho de Saul Steinberg

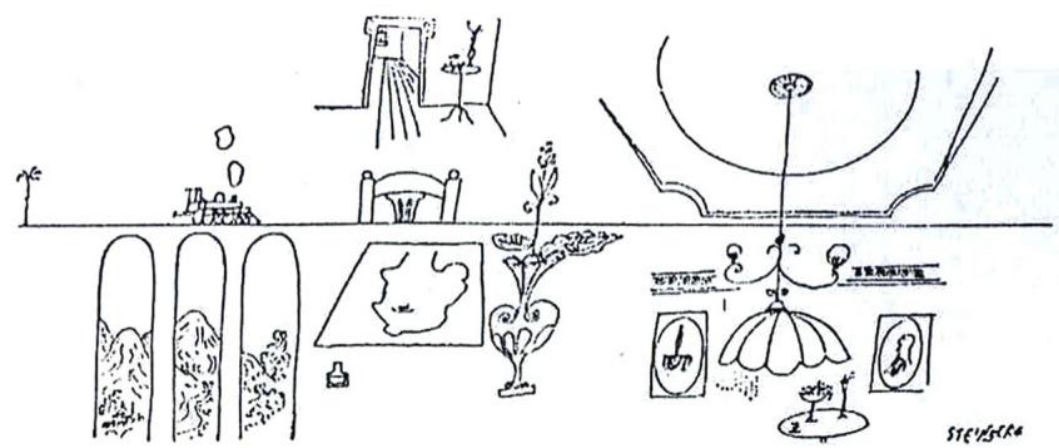

Fonte: Gombrich (1995, p. 251).

Os conceitos acima apresentados - estereótipo adaptado, princípio do etc. e teste de consistência - relacionam-se diretamente com as condições de produção e reconhecimento da imagem. A construção e a leitura da imagem fotojornalística - sua produção de sentido de uma maneira geral - implicam em considerarmos as discussões trazidas com estas noções desenvolvidas por Gombrich. E, com isso, é possível estabelecermos uma relação complementar entre uma análise discursiva e a psicologia da percepção, de forma que nos permita explicar alguns aspectos do processo de significação do fotojornalismo.

\section{Os processos de significação da imagem fotojornalística}

Com a intenção de explicar como os elementos constitutivos do fotojornalismo desenvolvem efeitos de sentido e estabelecem uma relação estável com o leitorado, à maneira de um contrato de leitura (VERON, 1983), propomos o desenvolvimento de categorias de análise que contemplem os seguintes pontos: a forma como a enunciação se manifesta nos discursos fotográficos; a multiplicidade de materiais significantes de que é composto o fotojornalismo (imagem e texto verbal) e, ainda, como a fotografia de imprensa, na semiose do jornal, participa na construção do acontecimento jornalístico. Com isso, as categorias elaboradas consideram os seguintes critérios:

a) relação entre texto e contexto - interessa-nos a relação que o discurso fotojornalístico desenvolve com o fato representado. Ou seja, uma relação forte com um acontecimento imediato, tomando a representação do acontecimento como o 
foco de sua significação ou, ao contrário, uma relação com um contexto social mais amplo, no qual a representação do acontecimento não é o foco principal do efeito de sentido, mas sim o caráter interpretativo do discurso;

b) relação temporal desencadeada - aqui importa-nos a relação que o discurso fotojornalístico estabelece com um acontecimento social e a temporalidade constituída pelo discurso, podendo orientar efeitos de sentido vinculados a um momento do "agora" ou a um momento do "então" próprio de um fato passado.

Considerando estes dois aspectos, constituímos as seguintes categorias: focalização, (2) enquadramento e (3) panorama simbólico. Essas três categorias permitem resgatar o sentido global do fotojornalismo e sua relação com o acontecimento midiático, conforme se pode ver a seguir:

Na categoria de focalização encontra-se uma estreita relação entre a imagem e o acontecimento representado. Nesse caso, a fotografia assume uma de suas históricas funções: a de atestar e comprovar um acontecimento ${ }^{5}$. Nessa categoria, temos uma relação "centrípeta" entre texto e contexto, que orienta a produção de sentido para o núcleo do acontecimento representado. Em sua relação temporal, esse tipo de construção de sentido conduz o leitor a um momento presente, um agora da representação fotográfica. A título de exemplo, podemos destacar a fotografia de Gil Passareli, de 1968, que recebeu o Prêmio Esso de fotografia desse mesmo ano (Figura 2). A imagem mostra um confronto de rua, no qual é possível ver um homem caído sendo agredido por outros ao seu redor. Em destaque, há outro homem de pé, na eminência de desferir um golpe naquele que se encontra no chão. A legenda da fotografia - De repente, a violência -, em sua relação com a imagem, impõe um efeito de sentido que coloca em relevo o acontecimento empírico - o tenso momento do tumulto.

Trata-se, como se pode observar, de uma imagem com uma série de figuras humanas, muitas delas sobrepostas, de forma que poucas são vistas por completo. Como nos explicar Gombrich (1995), através na noção de "princípio do etc.", não é necessário vermos por completo todas as figuras humanas, sendo que nossa percepção acaba por completar as figuras humanas que não aparecem por completo. Orientado pelo texto verbal que acompanha a imagem - que se relaciona com a fotografia através da lógica de "fixação", proposta por Barthes (1990a) - o leitor atribui sentido à cena sem necessitar ver a imagem

${ }^{5}$ Sobre este assunto, consultar Philippe Dubois (1994). 
por completo, já que determinadas figuras (por exemplo, os dois homens no terço esquerdo da fotografia, que estão posicionados de maneira a indicar golpes que serão desferidos contra o homem caído) dão a ideia do todo, de acordo com a ideia de "teste de consistência", de Gombrich (1995). Além disso, e que é característico de imagens dessa categoria, é a constituição por parte do leitor de uma projeção da sequência do acontecimento - nesse caso, uma pós-imagem, ou seja, uma construção do que aconteceu logo após a captação do quadro, haja vista a posição dos corpos dos dois homens que indicam os golpes que serão desferidos no indivíduo caído. Vê-se, assim, como os mecanismos de percepção do "princípio do etc." e do "teste de consistência" atuam, a partir da relação entre imagem e texto verbal, na produção de sentido e na construção do acontecimento.

Figura 2 - De repente, a violência.

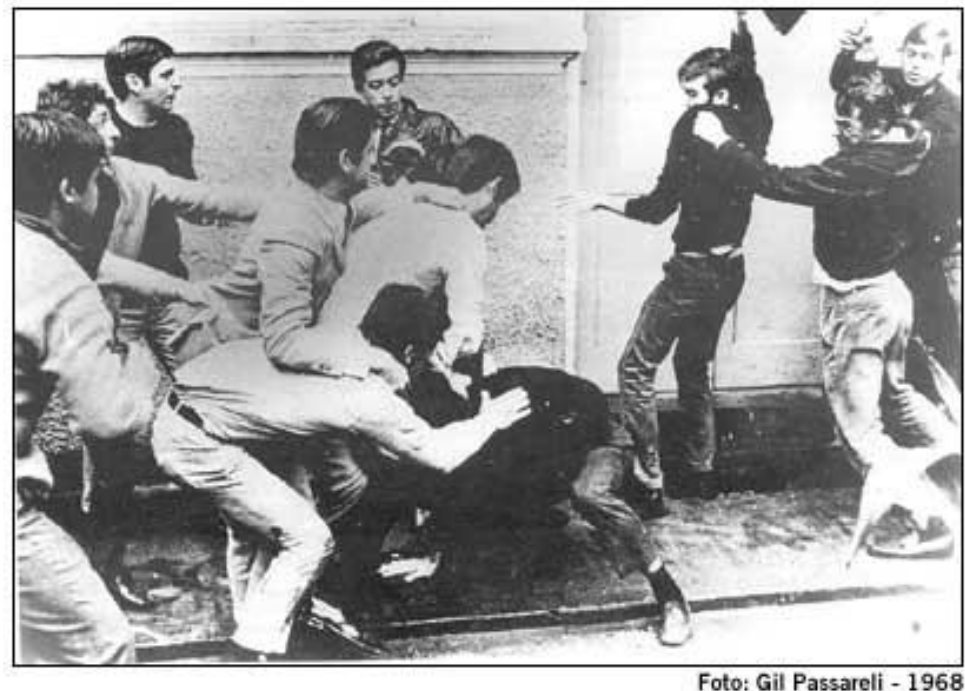

Fonte: Premio EXXON Mobil de Jornalismo (2015a).

Em seguida, temos a categoria denominada enquadramento. Nessas imagens - de caráter mais interpretativo -, a relação entre texto e contexto se constrói para além do fato representado, predominando uma força centrífuga na sua produção de sentido. Em sua dimensão temporal, esse tipo de imagem estabelece um momento presente, não tão centrado no acontecimento representado, mas ligado a um contexto mais amplo, de uma conjuntura.

Enquanto as imagens de focalização direcionam toda a produção de sentido para a ação mostrada, as imagens de enquadramento se aproveitam do fato representado e estabelecem uma relação de sentido que extrapola o que é visto na cena, resgatando outros 
acontecimentos. Servindo-nos de exemplo, temos a imagem do repórter fotográfico Carlos Menandro, que recebeu o Prêmio Esso de Fotojornalismo de 1986, publicada no mesmo ano no Jornal de Brasília (Figura 3). Em preto e branco, a fotografia montra, através de um ângulo bem particular, dois prédios públicos bastante conhecidos: a Câmara dos Deputados e o Senado Federal.

Figura 3 - Qualquer semelhança...

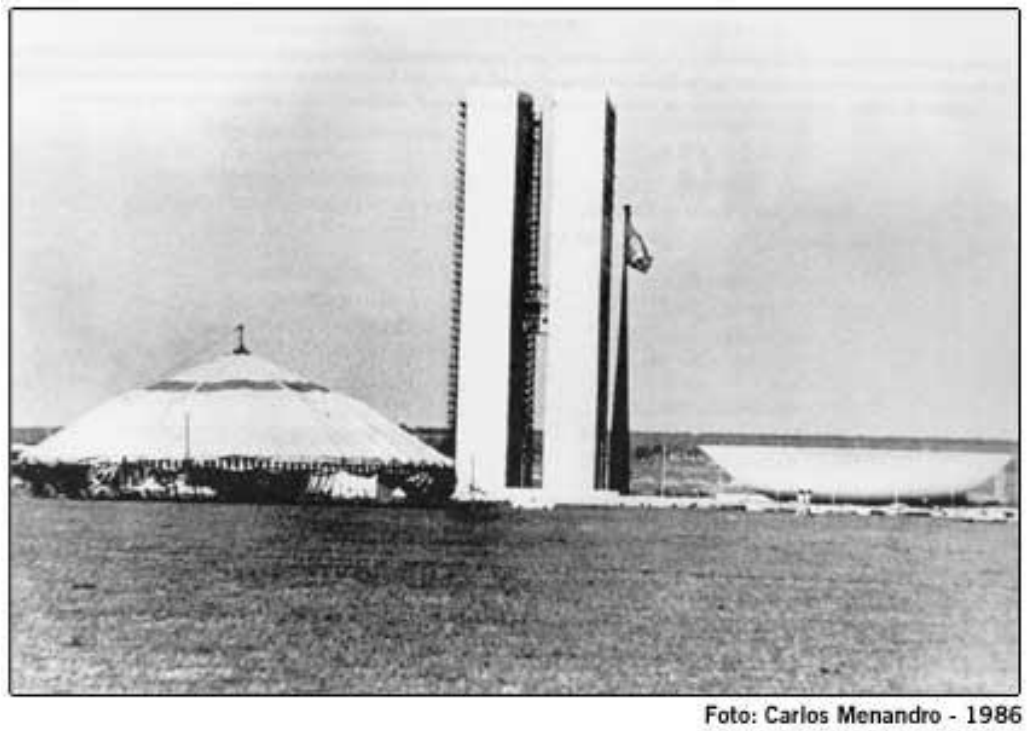

Fonte: Premio EXXON Mobil de Jornalismo (2015b).

O que em princípio não deveria trazer nenhuma surpresa - a imagem de dois importantes prédios da administração pública de Brasília - toma um aspecto bastante inusitado, pois, exatamente à frente de uma das edificações, está armada uma tenda de circo. A imagem foi produzida - aqui estamos nos referindo ao posicionamento cuidadoso que o fotógrafo assume diante da cena - de forma que a tenda tomasse a exata posição de uma das cúpulas do Congresso. Em função da semelhança em suas formas (entre a tenda e edifício público), a imagem do circo completa a imagem e substitui a parte ocultada do prédio. Contudo, é ainda a relação que o texto tem com a imagem que garante um efeito de sentido que remete o leitor a algo que não está exatamente ali, na fotografia. Assim, a interação entre a legenda - Qualquer semelhança... - e a imagem do circo sobreposta ao prédio público produz um sentido irônico e crítico que não está de fato no acontecimento empírico representado. Temos, assim, esse efeito de sentidos que dilata o acontecimento empírico e o supera, criando um vínculo com outros sentidos possíveis. 
Assim, o leitor, a partir da identificação de alguns elementos - referimo-nos ao prédio público parcialmente apresentado - completa a cena, pois, conforme evidencia Gombrich (1995), a partir de sua noção de "princípio do etc.", não é necessário que o coenunciador tenha a sua disposição todos os elementos de uma situação, pois ele "completa" a cena a partir dos elementos que lhe são dados pela imagem. Ou seja, o prédio público não aparece por completo, mas o leitor é capaz de agregar à imagem o que está ausente.

0 deslizamento de sentidos provocado pela relação entre imagem e texto verbal, que resvala para a ironia, passa por uma avaliação do leitor, que procura na imagem o seu reforço (sua confirmação), de acordo com a lógica do "teste de consistência", proposto por Gombrich (1999): são os sentidos socialmente estabilizados da ideia circo (brincadeira, improviso, trapalhada, etc.), que são sobrepostos aos sentidos da política brasileira, representados pelos prédios que formam o Congresso Nacional - só se confirmam para o leitor após ele verificar, na fotografia, a consistência dessa proposta de sentidos que surge da relação entre a imagem e o texto verbal.

A terceira categoria, denominada panorama simbólico, refere-se àquelas imagens que, em sua relação discursiva com o tempo, determinam a ideia de um contexto pretérito que perdura no tempo, um passado que sempre retorna. Sua dinâmica entre texto e contexto vincula um fato presente a acontecimentos do passado, geralmente de relevância histórica. É esta relação, que aproxima um fato noticiado com um fato histórico, estabelecendo uma vinculação com o quê já aconteceu que caracteriza a fotografia do tipo panorama simbólico.

Exemplificando, temos a imagem de Luiz Morier, veiculada no Jornal do Brasil, em 1983, e ganhadora do Prêmio Esso de Jornalismo do mesmo ano (Figura 4). No primeiro plano da fotografia, do lado esquerdo do quadro, vemos um policial fardado, conduzindo cinco suspeitos de delito. No segundo plano da imagem, aparecendo de corpo inteiro (exceto um deles, que está coberto pela imagem do policial), estão os suspeitos detidos, amarrados pelo pescoço com uma corda, que prende uns aos outros. Em sua relação com o texto verbal - a imagem é acompanhada da legenda "Todos negros" -, a fotografia conduz o leitor a um efeito de sentido no qual o acontecimento representado - a captura e prisão de suspeitos faz forte remissão a um acontecimento histórico: a captura e punição de escravos. Com isso, fatos que só podiam ser vistos no período da escravidão parecem estar ainda presentes em nossa sociedade.

Além dessa relação entre imagem e texto verbal, a ação representada na fotografia em muito se assemelha (em seus aspectos figurativos) a padrões de imagem já fixados na 
cultura do leitorado, à maneira de estereótipos visuais. Em outras palavras: o estereótipo cristalizado na cultura atua, nesse caso, como uma espécie de imagem modelo, que serve de base para o fotógrafo adaptar de acordo com a necessidade que a situação lhe impõe, bem de acordo com a noção de "estereótipo adaptado", de Gombrich (1995). 0 alinhamento e o posicionamentos dos corpos dos presos, o fato de serem negros, a postura do policial, que muito se assemelha à imagem do antigo Capitão do Mato, fazem clara remissão às gravuras e desenhos que representam a condução de escravos - imagens que cristalizaram sentidos e formaram estereótipos visuais.

Figura 4 - Todos Negros

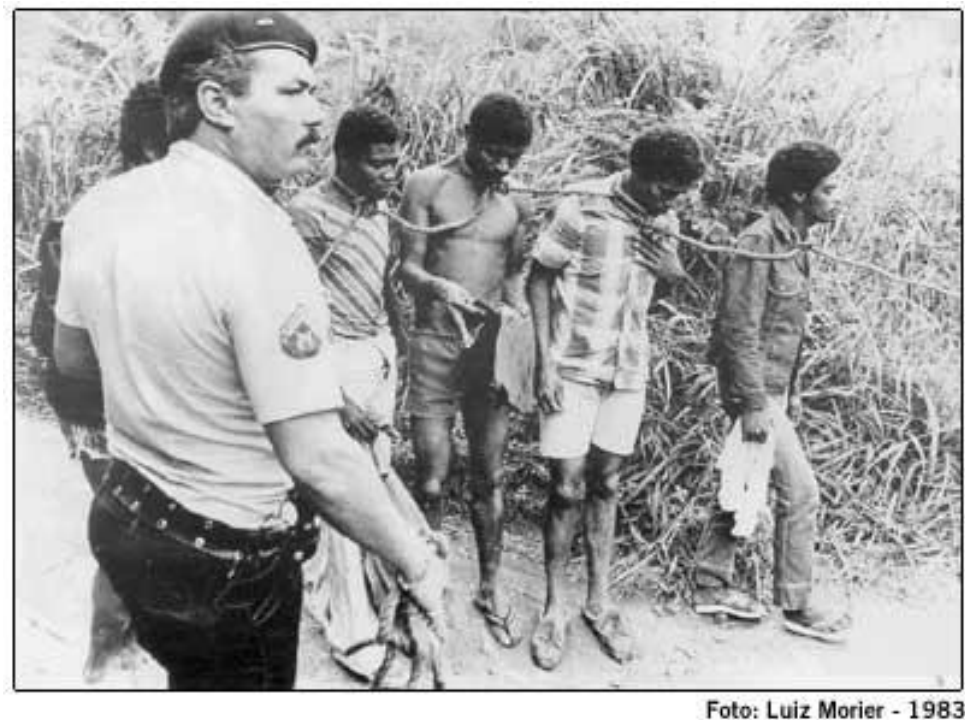

Fonte: Premio EXXON Mobil de Jornalismo (2015c).

Com essas três categorias aqui discutidas, pretendemos evidenciar como ocorre a construção do discurso fotojornalístico, priorizando sua relação temporal e a interação entre texto e contexto. Mas, como dissemos anteriormente, interessa-nos também compreender como os elementos plásticos e visuais, próprios da imagem, participam no desenvolvimento dessas categorias e suas relações de sentido.

De fato, o que orienta o desenvolvimento das categorias é algo da ordem do efeito de sentido, de uma semiose do discurso fotojornalístico, como visto acima. Tanto é assim que uma análise mais cuidadosa mostra que em uma determinada categoria pode haver fotografias com uma organização visual bastante diversa. Ou seja, aspectos plásticos ou figurativos não são a chave de análise para a tipologia anteriormente propostas. Entretanto, 
o comportamento desses aspectos próprios da imagem - e sua contribuição para a produção de sentido -, em cada uma das três categorias de análise proposta, interessa-nos, à medida que permitem entender o funcionamento discursivo da imagem fotográfica de imprensa.

Nessa perspectiva, as imagens de focalização são caracterizadas pela produção de um sentido direcionado ao acontecimento representado, ao fato que está sendo mostrado pela imagem. Sua força discursiva, com isso, está centrada no histórico valor comprobatório do dispositivo fotográfico - socialmente constituído. Isso não quer dizer que apenas esse tipo de fotografia possui tal característica, mas que esse é o traço discursivo marcante da categoria focalização.

Sendo o sentido direcionado ao acontecimento empírico o seu traço definidor, a representação da ação e do movimento é a principal característica plástica e visual dessas fotografias. Dessa forma, o produtor de imagens deve considerar que a impressão de ação é marcada por elementos de nossa experiência empírica do movimento (GOMBRICH, 1995). Ou seja, a representação adequada do movimento é garantida pelo destaque de certos elementos formais presentes na percepção direta da ação. Entre os possíveis recursos que acentuam a movimentação, temos: a fixação do movimento, o realce da expressão facial e do corpo e a organização e seleção do enquadramento.

Em relação à fixação da ação, trata-se de registrar a imagem em um dado momento que concentre a intensidade do movimento dos atores na cena. Esse recurso é explicado pala capacidade do leitor de projetar tanto a continuidade do movimento, a pós-imagem, como os instantes que o antecedem, a pré-imagem. É, de certa forma, a capacidade de atribuir um valor narrativo à imagem, introduzindo nela um "antes" e um "depois" do momento representado. Assim, quando leitor observa, em uma imagem, alguém que estende o braço indicando uma direção, seu olhar acompanha a direção apontada. Do mesmo jeito, quando há uma fotografia de esporte na qual é fixado o exato momento em que o jogador está prestes a chutar a bola, o leitor projeta o movimento do chute em direção ao gol (GOMBRICH, 1995; AUMONT, 1993).

Outro recurso bastante utilizado na focalização é o realce da expressão facial. Considerando que essas imagens, em seu efeito de sentido, remetem para a ação representada, pode-se também pôr nesta categoria as fotografias de entrevistas, comícios, depoimentos e eventos públicos. Contudo, não devemos confundir estas fotografias com aquelas que Eliseo Verón (1983) classifica como "pose" - as imagens em que o fotografado tem conhecimento da presença do fotógrafo e, por isso mesmo, deixa-se fotografar - ou 
"retórica das paixões" - aquelas fotografias em que a relação entre imagem e texto verbal atribui outro sentido à expressão do fotografado. As imagens que indicamos como focalização direcionam a interpretação para um acontecimento no qual, geralmente, o fotografado não tem controle da produção de imagens, em função destas serem realizadas durante um acontecimento qualquer. Além disso, aqui ocorre uma produção de sentido que está voltada para o acontecimento, diferentemente das duas categorias estabelecidas por Verón (1983). Assim, a expressividade de um rosto tem, dentro da discursividade fotojornalística, um sentido canalizado para o fato representado e traz para o leitor a informação visual própria do acontecimento.

Além dos recursos citados, temos a organização e seleção do enquadramento, que estão relacionadas à composição do quadro - organização dos elementos internos da cena. A fim de acentuar a ação, podemos destacar alguns fatores como: (1) o realce da perspectiva, que permite uma maior impressão de deslocamento e espaço na imagem (AUMONT, 1993); (2) o direcionamento da atenção do leitor para determinadas partes da imagem, através da nitidez da cena - referimo-nos ao recurso da profundidade de campo, que permite selecionar as áreas nítidas da fotografia (AUMONT, 1993; SOUSA, 2004); (3) o tipo de plano fotográfico, que permite destacar uma expressão facial ou outro detalhe da imagem ou, ao contrário, um plano aberto, com diversos elementos, que acentuam o impacto de uma imagem de multidão, por exemplo. Além disso, a seleção das imagens, em um processo posterior de edição, permite a escolha do enquadramento mais adequado para a ênfase da ação (SOUSA, 2004).

Se, por um lado, as imagens de focalização conduzem a interpretação para o acontecimento empírico, direcionando o leitor para o núcleo do fato, o momento da representação, o mesmo não se pode dizer das imagens de enquadramento ou panorama simbólico. Na primeira categoria - a focalização -, prevalece o caráter de autenticidade e comprovação da imagem, seu valor indicial, o "isto foi" de barthesiano. Assim, trata-se de um efeito de sentido mais simples e menos interpretativo, enquanto nas outras duas categorias há um jogo de sentidos que convoca um plano de significação que está fora da representação e do acontecimento.

No caso das imagens de enquadramento - aquelas fotografias que estabelecem uma relação temporal ligada a um momento presente ou uma conjuntura social imediata -, não há um traço visual que as caracterize (o que não impede a existência de estereótipos), mas um deslizamento de sentido que parte de um dado visual qualquer da imagem e estabelece 
outra ordem de significados que não está presente na fotografia. Assim, observando o exemplo anterior de enquadramento (Figura 3), pode-se dizer que, a partir de um dado elemento interno da imagem, a relação entre fotografia e texto desloca o sentido da imagem para além do seu valor denotativo.

Em relação às imagens que compõem a terceira categoria - panorama simbólico -, o funcionamento discursivo acontece de outra forma, embora haja elementos em comum com o tipo anterior. Enquanto na fotografia de enquadramento há uma perda considerável de seu valor fatual em detrimento de um significado segundo, externo à imagem, no panorama simbólico não ocorre o mesmo. Nesta última temos uma adição de outro significado, sem que se perca o sentido do acontecimento empírico. Desta maneira, temos dois sentidos que são aproximados em função da relação entre imagem e texto e também do plano visual da imagem.

Podemos destacar, no plano visual e plástico desta categoria de imagens, a existência de um padrão já estabelecido na cultura, um estereótipo visual que desencadeia a relação de sentido entre o acontecimento noticiado e um momento do passado. No caso de nosso exemplo (Figura 4), a fotografia dos suspeitos amarrados pelo pescoço, percebe-se que o efeito de sentido encontra apoio desde o elemento visual até sua relação com texto. Ou seja, tanto o estereótipo visual (a própria fotografia) quanto a relação entre imagem e legenda trazem o sentido de resgate de um momento pretérito, aproximando o agora e o passado, estabelecendo a ideia de uma conjuntura social crônica.

\section{Considerações}

Mesmo sendo a Análise de Discurso um campo de conhecimento que se dedica a materiais significantes diversos, sua relação com o estudo do signo linguístico é, além de historicamente tradicional, também mais forte conceitual e metodologicamente, quando comparado aos estudos acerca da imagem.

Desta forma, propusemos aqui alguns elementos para o desenvolvimento de uma análise que concentra sua atenção nos aspectos formais da fotografia, principalmente o fotojornalismo, a fim de encontrar seus modos de interação com o leitor. Neste ponto, os estudos vindos de outras áreas do conhecimento - como é o caso das pesquisas de E. Gombrich $(1995,1999)$ - mostram-se compatíveis e aplicáveis dentro de uma perspectiva discursiva que procura buscar na imagem, em seus elementos intrínsecos, o desenvolvimento de uma enunciação. 
Reiteramos aqui a ideia de que a Análise de Discurso privilegia um efeito de sentido global, não negligenciando o estudo da matéria não verbal. Contudo, ainda percebemos a necessidade de retirar a imagem de sua dependência frente ao texto verbal ou mesmo de tentativas de análise que buscam uma compreensão dentro de um esquema linguístico de funcionamento do fotográfico. Assim, reforçamos a necessidade do desenvolvimento de mecanismos de análise que contemplem as especificidades da imagem.

Acreditamos que essa proposta metodológica é um passo inicial na compreensão da fotografia nos meios de comunicação e suas relações de sentido com o leitor, desenvolvidas ao longo do tempo. Contudo, pensamos que o aprofundamento do estudo discursivo da imagem fotográfica passa, em grande parte, pela busca dos recursos de enunciação da imagem e suas formas de convocar o leitor e posicioná-lo no processo da leitura.

\section{Referências}

AUMONT, Jacques. A imagem. Campinas: Papirus, 1993.

BARTHES, Roland. A câmara clara: notas sobre a fotografia. 3. ed. Rio de Janeiro: Nova Fronteira, 1984.

BARTHES, Roland. A mensagem fotográfica. In: BARTHES, Roland. o óbvio e o obtuso: ensaios críticos III. Rio de Janeiro: Nova Fronteira, 1990a, p. 11-25.

BARTHES, Roland. A retórica da imagem. In: BARTHES, Roland. 0 óbvio e o obtuso: ensaios críticos III. Rio de Janeiro: Nova Fronteira, 1990b, p. 27-43.

DUBOIS, Philippe. 0 ato fotográfico e outros ensaios. Campinas: Papirus, 1994.

FIORIN, José Luis. As astúcias da enunciação: as categorias de pessoa, espaço e tempo. 2. ed. São Paulo: Ática, 1999.

FREUND, Gisèle. Fotografia e sociedade. São Paulo: Vega, 1989.

GOMBRICH, Ernest. Arte e ilusão: um estudo da psicologia da representação pictórica. São Paulo: Martins Fontes, 1995.

GOMBRICH, Ernest. Meditações sobre um cavalinho de pau: e outros ensaios sobre teoria da arte. São Paulo: EDUSP, 1999.

JOLY, Martine. Introdução à análise da imagem. 4. ed. Campinas: Papirus, 1996.

LIMA, I. A fotografia é a sua linguagem. 2. ed. Rio de Janeiro: Espaço e Tempo, 1988. 
MAINGUENEAU, D. Termos-chave da análise do discurso. Belo Horizonte: Editora da UFMG, 1998.

METZ, Christian. Para além das imagens. In: METZ, Christian et al. A análise das imagens. Petrópolis: Vozes, 1973. p. 1-18.

ORLANDI, Eni. Análise de discurso: princípios e métodos. Campinas: Pontes, 1999.

PINTO, Milton José. Semiologia e Imagem. In: BRAGA, José Luiz. A encenação dos sentidos: mídia, cultura e política. Rio de Janeiro: Diadorim/COMPÓS, 1995.v. 1.

PREMIO EXXON Mobil de Jornalismo. De repente, a violência. [S.I.], 2015a. Disponível em: <http://www.premioexxonmobil.com.br/site/popup/pop_fotografia_1968c.htm>. Acesso em: 10 mar. 2016.

PREMIO EXXON Mobil de Jornalismo. Qualquer semelhança... [S.I.], 2015b. Disponível em: <http://www.premioexxonmobil.com.br/site/popup/pop_fotografia_1986.htm>. Acesso em: 10 mar. 2016.

PREMIO EXXON Mobil de Jornalismo. Todos negros. [S.I.], 2015. Disponível em: <http://www.premioexxonmobil.com.br/site/popup/pop_fotografia_1983.htm>. Acesso em: 10 mar. 2016.

SOUSA, Jorge Pedro. Fotojornalismo: introdução à história, às técnicas e à linguagem da fotografia na imprensa. Florianópolis: Letras Contemporâneas, 2004.

VERON, Eliseo. A produção de sentido. São Paulo: Cultrix,1980.

VERON, Eliseo. El análisis del contrato de lectura: un nuevo método para los estudios de posicionamiento en los soportes de los media. In: INSTITUT DE RECHERCHES et d'études publicitaires (Org.). LES MEDIAS: experiences, recherches actuelles, aplications. Paris: IREP, 1983. p. 60-88.

VILCHES, L. Teoría de la imagen periodística. Barcelona: Paidós, 1987.

\title{
Speech and Image: methodological possibilities for a discursive analysis of contemporary photojournalism
}

\begin{abstract}
It is known that the different approaches developed within the Discourse Analysis had mainly been occupied with discursive practices drawn from linguistic materials. This makes consistent the methodological possibilities that are focused on the study of verbal texts, as literature, print journalism or advertising, for example. From this context, we present the limits and
\end{abstract}


possibilities of an analysis methodology of photojournalistic image, based on a discursive view of language. Therefore, the study proposes a methodology that considers the theoretical assumptions of Discourse Analysis and the possible contributions from the psychology of perception, developed by Ernst Gombrich for the study of images. As a resulted, it is presented a set made up of three categories of the photojournalism analysis, which considers the historical and ideological implications and its relations with non-verbal matter in the constitution of semiosis of print journalism.

\section{Keywords}

Photojournalism. Discourse analysis. Enunciation. Discursive positioning. Psychology of perception.

Recebido em 21/05/2016

Aceito em 13/10/2016 